NASA Technical Memorandum 81720

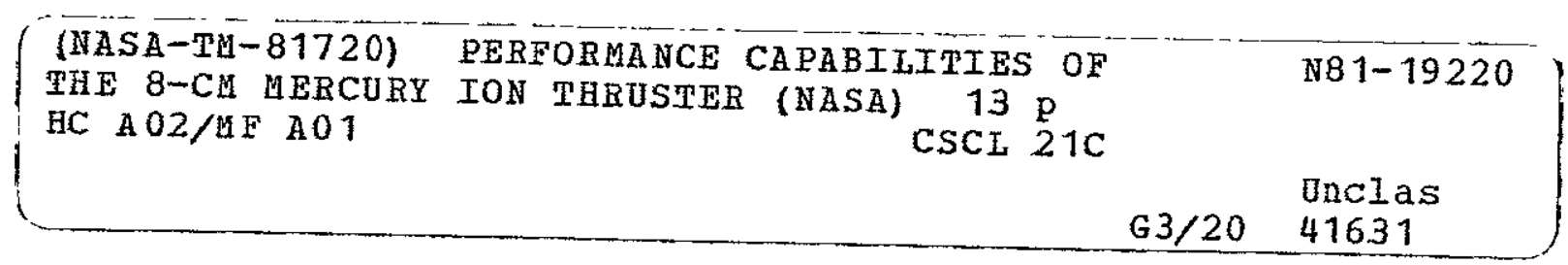

\title{
Performance Capabilities of the 8-cm Mercury Ion Thruster
}

M. A. Mantenieks

Lewis Research Center

Cleveland, Ohio

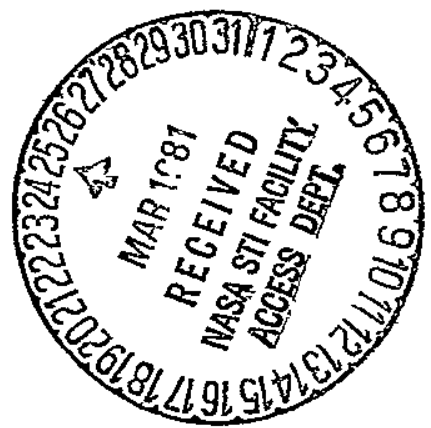

Prepared for the

Fifteenth International Electric Propulsion Conference cosponsored by the American Institute of Aeronautics and Astronautics, the Japan Society for Aeronautical and Space Sciences, and Deutsche Gesselschaft fur Luft- und Raumfahrt Las Vegas, Nevada, April 21-23, 1981 
PERFORMANCE CAPABILITIES OF THE, 8-cm MERCIURY ION THRUSTER

\author{
M. A. Mantenieks \\ National Aeronautics and Space Administration \\ Lewis Research Center \\ Cleveland, Ohio 44135
}

\section{Abstract}

The 8-cm Hg ion thruster system was developed primarily to provide $\mathrm{N}-\mathrm{S}$ station keeping of satellites with masses up to about $1800 \mathrm{~kg}$. The on-orbit propulsion requirements of recently proposed Large Space Systems (LSS) are beyond the capabilities of the present 8-cm thruster system operated at baseijne conditions. This paper presents a preliminary characterization of the performance capabiluties of the 8-cm thruster in order to initiate an evaluation of its application to LSS propulsion requirements. With minor thruster modifications, the thrust was increased by about a factor of four while the discharge voltage was reduced from 39 to 22 volts. The thruster was operated over a range of specif ic impulse of 1950 to 3040 seconds and a maximum total effrciency of about 54 percent was attained. Pre7 ininary analysis of component lifetimes, as determined by temperature and spectroscopic 17ne intensity measurements, indicated acceptable thruster lifetimes are anticipated at the high power level operation. No attempts were made as yet to optimize thruster performance.

\section{Introduction}

The $8-\mathrm{cm}, 5.0 \mathrm{mN} \mathrm{Hg}$ ion thruster system was primarily developed to provide $\mathrm{N}-\mathrm{S}$ station keeping of geosynchronous satellites with masses up to about $1800 \mathrm{~kg}$. The thruster is a lso capable of providing high precision attitude control, East-west station keeping, and station-change propulsion functions. 1,2 with the advent of the Shuttle, many missions have been recently proposed which employ Large Space Systems (LSS). $3-5$ Such missions include space based radar, large communications platforms, and space laboratorles. The masses, configurations, and orbits, of many of the proposed LSS imply on-orbit propulsion requirements beyond the capabilities of the present 8-cm thruster system operated at baseline conditions. This situation is illustrated in Fig. 1, which is based on data of Ref. 2. Figure 1 shows, for example, that for a configuration of two north and two south $8-\mathrm{cm}$ thrusters, with two operating for 6 hours about each node, spacecraft masses of up to only about $1800 \mathrm{~kg}$ can be accormodated.

For LSS with large area to mass ratios, solar pressure effects also have to be considered. The solar pressure changes the eccentricity of a synchronous equatorial orbit, resulting in an apparent daily east-west oscillation6. For light weight structures such as Space Based Radar, the total impulse, and hence the propellant requirements, can increase by an order of magnitude when effects of solar pressure are included (F,g. 2). Such effects $1 \mathrm{mply}$ a need for increased capabilities of the onorbit propulsion systems.

The objective of this study was to present an initial characterization of the performance capabilities and constraints of the $8-\mathrm{cm}$ thruster and to allow a preliminary evaluation of its possible application to LSS propulsion requirements. In particular, the achievable levels of thruster performance were investigated at high power levels along with preliminary evaluation of thruster lifetime.

\section{Apparatus and Procedure}

\section{Thruster}

The 8-cm thruster with dished grids and a low open area accelerator grid used in this study has been described in Ref. 7. It was a SIT 8 thruster modified to conform to the 8-cm EMT design. The following modifications were made on the baseline 8-cm thruster: (1) copper strips were attached from the vaporizer-isolator interface to the ground screen to act as heat sinks so that vaporizer thermal control could be extended to higher discharge power levels, (2) the rolled forl insert in cathodes was replaced in all tests with a solid impregnated insert to improve the cathode performance and repeatability. Cathodes with both $0.25 \mathrm{~mm}$ (baseline design) and $0.73 \mathrm{~mm}$ orifices were tested.

\section{Power Supplies and Facility}

The power supplies consisted of laboratory types described in Ref. 7, with the discharge and screen grid supply capabilities increased to 4.5 and 1.0 amps, respectively. The tests were performed in a $1.5 \times 6.1$ meter vacuum facjility operating at a no load pressure in the $4 \times 10^{-5}$ to $1.3 \times 10^{-4} \mathrm{~Pa}$ $\left(3 \times 10^{-7}\right.$ to $1 \times 10^{-6}$ Torr $)$ range.

Optical Spectrometer Instrumentation

A Jarre 1-Ash, $0.5 \mathrm{~m}$ Ebert scanning spectrometer with an electric drive was used with a strip chart recorder to measure the spectral radiation emanating from the 8-cin thruster. The spectrometer was located at the opposite end of the vacuum facility and viewed the thruster on axis through a quartz window. A slit size of 75 microns was used. The excited atomic molybdenum, MoI $(3798 \AA$ ), atomic mercury, HgI ( $3802 \AA)$, singly ionized mercury ion, HgII $(3806 \AA)$ and doubly conized mercury ion, HgIII $(4797 \AA)$, spectra] line intensities were measured as a function of thruster parameters.

\section{Thruster Operation}

The discharge chamber of the $8-\mathrm{cm}$ thruster operates with only one propellant flow control loop (as compared to two for of the $30-\mathrm{cm}$ thruster). The control loop adjusts the vaporizer power to provide the correct propellant flow rate for obtaining a desired discharge voltage. The beam current for the baseline thruster is controlled by varying the discharge current at a given discharge voltage. The $8-\mathrm{cm}$ baseline discharge voltage of 39 volts, and discharge current of $0.5 \mathrm{~A}$ results in a beam current of $\sim 72 \mathrm{~mA}$. Higher beam current levels were achieved in this study by operating the thruster at higher discharge currents, higher propellant flow rates, and lower discharge voltages. As higher beam cur- 
rents were obtained, increases of the screen and. accelerator voltages were necessary to prevent excessive ion interception by the accelerator grid.

The operating ranges of the thruster parameters were limited by the vaporizer thermal control characteristics and the discharge current power supply.

\section{Results and Discussion}

\section{Thruster Performance}

Figure 3 shows the beam currents obtained with the $0.25 \mathrm{~mm}$ cathode configuration as a function of discharge current at various discharge voltages. It is evident that increasing the discharge.current beyond the baseline value of $0.5 \mathrm{~A}$ (discharge voltage of 39 volts) did not result in corresponding increases in the bean current. However, the beam current did increase whth increasing discharge current when the discharge voltage was reduced by increasing the propellant mass flow rate. At discharge voltages of 32 and 35 volts, the beam current began to decrease above discharge currents of 3.0 and 4.0 ; respectively. This occurred because as the discharge current was increased above these values, the flow rate started to decrease in order to keep the discharge voltage constant. The resulting lower flow rate led to a decrease in the beam current. At lower discharge volt ages this decrease was not observed at the available discharge current values.

Increase in the propellant flow rate at a given discharge current resulted in reaching a minimum discharge voltage, at which point further increases. in propellant flow rate resulted in increases in discharge voltage and decreases in beam current. The minimum discharge volt age for the $0.25 \mathrm{~mm}$ cathode orifice ranged from about $26 \mathrm{~V}$ at a discharge current of $1.5 \mathrm{~A}$ to $23 \mathrm{~V}$ at $4.5 \mathrm{~A}$.

The range of thruster operation shown in Fig. 3 was limited at high discharge currents by the $4.5 \mathrm{~A}$ discharge current supply limit and at low discharge voltages and currents by the limt of the vaporizer heater power supply (or avajlable propellant flow).

The characteristic increase of beam current with decreasing discharge voltage at various discharge currents can be observed in Fig. 4 for both cathode orifices. The beam current increased with decreasing discharge voltage in an approximately linear fashion for the $0.25 \mathrm{~mm}$ cathode orif $7 \mathrm{ce}$ tests (Fig. 4(a)). The maximum beam current of $264 \mathrm{~mA}$ was 3.7 times that of the 8-cm thruster operated at the baseline condition and represents an average current density of about $5.3 \mathrm{~mA} / \mathrm{cm}^{2}$.

The discharge current-voltage characteristics of the large orifice cathode were somewhat different from that of the $0.25 \mathrm{~mm}$ cathode geometry. Two distinctive slopes were evident for discharge currents greater than $2 \mathrm{~A}$, as compared to one slope in $\mathrm{Fig}$. $4(a)$, but the maximum obtainable beam current of $270 \mathrm{~mA}$ was about the same as for the smaller cathode orifice.

The maximum bean current attainable at a given discharge current increased linearly with the discharge current, Fig. 5 . The $0.73 \mathrm{~mm}$ cathode geometry data again displayed a somewhat different characteristic as compared to the smaller cathode orifice tests.
The operation of the thruster with the two orifice sizes differed in still another respect. For the small cathode orifice, the maximum beam current attainable for a given discharge current corresponded to the point of minimum discharge voltage. In the large orifice tests, the maximum beam current was reached at discharge voltages somewhat higher than the min mmum attainable discharge voltage.

It appears that higher beam currents for the cathode geometries investigated could have been attained from the 8-cm thruster of higher discharge currents had been available because neither the breakdown voltage nor the perveance limit of the grids (see Fig. 6) had been reached. It is also probable that higher beam currents at a given discharge current (lower watts/beam ampere) cou Td have be attained if the thruster geometry and magnet ic fields had been optimized for operation at high discharge power.

The perveance limits of the dished grods with a gap of 0.50 min is shown in Fig. 6 for the small cathode orifice geometry. The maximum attainable current density was about the same as that of the 30-cm thruster. 8

The maximum mass utilization values (Fig. $7(a)$ ) of 86-92 percent were obtained between discharge voltages of 26-35 volts with the $0.25 \mathrm{~mm}$ orifice cathode. These values compared well with the EMT baseline value of about 84 percent.

The propellant mass ut lization curves in Fig. '. 7 (a) had the same general characteristics at the various discharge current values. The utilization increased at low discharge voltage with increasing discharge voltage, reached a maximum, then decreased and again began to increase at high discharge voltages. The pornt of maximum ut lization moved to lower discharge voltages with increasing discharge current. In the lower discharge voltage region, the propellant utilization at a given discharge voltage was found to increase with increasing discharge current.

The mass utilization of tests with the $0.73 \mathrm{~mm}$ orifice (Fig. 7(b)) were not as high as with the smaller cathode orifice and the shape of the curves for a given discharge current were different from those of Fig. $7(a)$. The maximum utilization was found to be at the highest operated discharge voltage, except at a discharge current of $1.0 \mathrm{amp}$. At this discharge current, the maximum utilization was found at a discharge voltage of $30 \mathrm{~V}$.

The ron production costs at yarious discharge currents are shown in Fig. 8 for the small orifice cathode tests. For discharge currents greater than 1.0 A, the minimum ion production costs at a given discharge current ranged between 310 and 360 watts per beam ampere (W/A), as compared to about $250 \mathrm{~W} / \mathrm{A}$ for the baseline $8-\mathrm{cm}$ thruster. (The keeper costs of 3 to $6 \mathrm{~W} / \mathrm{A}$ were not included in the calculations of Fig. 8.) The ion production cost at a given discharge current decreased significantly with decreasing discharge voltage or increasing beam current. In addition, the ion production costs decreased at a given discharge voltage with decreasing discharge current and beam current.

The production costs with the large cathode orifice had the same characteristics as with the 
sma1l cathode orifice, however, somewhat lower costs were achieved at large discharge currents and Jow discharge voltages.

Thrust, specific impulse and total thruster efficiency are shown in Fig. 9 as a function of thruster input power for the small orifice cathode operated at a discharge voltage of 26 volts. The characteristics of the performance parameters were generally insensitive to the discharge voltage and 26 volts was selected to display thruster performance at the upper range of input power (Fig. 3). The following assumptions were made in detemining the data for Fig. 9: (a) a thrust loss factor of 0.95 , to account for losses due to ion bean divergence and doubly charged jons, (b) constant power loss of 14 watts due to keeper and vaporizer operation of the main and neutralizer cathodes, (c) neutralizer mass flow rate (in equivalent amperes) of 10 percent of the ion beam current.

The input power was increased by increasing the beam current and the discharge power. As the beam current increased it was necessary to increase the total accelerating voltage to avoid ion defocusing in the grids (Fig. 6). For this reason the beam voltage increased with increasing input power which resulted, in conjunction with the utilization efficlency variation with beam current ( $F 1 g$. $7(a))$, in the specific impulse characteristics shown in Fig. 9. This figure shows that while the thrust increased almost linearly with increasing input power, the total efficiency reached a maximum and then remained almost constant. This leveling off is due to a decrease of the electrical efficiency at the high input power. Over the entire range of thruster operation (not shown in $\mathrm{Fig} .9$ ), the speci$f$ ic impulse ranged from 1950 to 3040 seconds. whereas the thrust varied from 5.3 to $20.4 \mathrm{mN}$, as compared to $4.8 \mathrm{mN}$ thrust at the baseline conditions. The highest tota 1 efficiency of 55 percent was obtained at a discharge voltage of 24 volts and input power of $0.49 \mathrm{~kW}$. It is believed, however, that optimization of thruster perfornance at high input power levels should result in improved performance.

\section{Spectroscopic Intensity Measurements}

The optical spectrometer has proven itself to be a useful tool in helping to evaluate thruster component lifetimes: ${ }^{9}, 10$ The spectral line intensity of molybdenum can be related to the sputtering rate of the molybdenum screen grid if the thruster operating conditions are kept constant.

A rough comparison may be made between the sputtering rates of the $8-\mathrm{cm}$ and $30-\mathrm{cm}$ thrusters, at the same operating conditions, by comparing the rat 10 of the excited atomic molybdenum (MoI $3798 \AA$ ) and the atomic mercury ( $\mathrm{HgI} 3802 \AA)$ intensities of the two thrusters (Fig. 10). The intensity ratios are shown as a function of average beam current density because this parameter is proportional to the average plasma density inside the discharge chamber. The data of the $30-\mathrm{cm}$ thruster were taken at constant jon production cost, whereas because of the single control loop of the 8-cm thruster, this was not possible for the smaller thruster. The intensity ratios of the 8-cm thruster at a given beam current density was less than that of the $30-\mathrm{cm}$ thruster at a discharge voltage of 35 volts but slightly higher at a discharge voltage of 32 volts.
Therefore, it is likely that the sputtering rates of the two screen grids at these operating conditions should be about the same. The lifetime of the $30-\mathrm{cm}$ thruster at baseline conditions has shown to have an operating lifetime of about 15,000 hrs. 9 From known sputtering behavior, it may be reasoned that the sputtering rate of the 8-cm screen grid operating at low discharge voltages and high beam current may be about the same as the sputtering rate of the $30-\mathrm{cm}$ thruster grid operating at the baseline cond $1-$ tions. A life test is necessary, however, to verify this comparison.

Test of the $30-\mathrm{cm}$ thruster 9,10 have shown (that the environment of the vacuum facility may have a significant effect on the sputtering rates of thruster components if the facility pressure is not sufficiently low enough. Preliminary tests (Fig. II) ind icated that operation of the 8-cm thruster at a high beam currents and low discharge voltages should not be affected by background pressure if operated at pressures of about $1 \times 10^{-4} \mathrm{~Pa}$ ( $1 \times 10^{-6}$ Torr) or less. - Figure 10 is similar to curves obtained with the $30-\mathrm{cm}$ thruster operating at higher discharges voltages and somewhat lower beam. current densities. However, the knee at the top of the curve, which marks the beginning of the pressure effect on sputtering rates, 11 appears in $\mathrm{Fig}$. 11 at higher than expected pressures when compared to the $30-\mathrm{cm}$ data. The reason for this is not known.

Thruster Component Temperature Measurements

To ascertain the 8-cm thruster component integrity under high power operation, 9 thermocouples were installed on critjcal thruster components. Figure 12 shows typical temperatures of five of these components as a function of discharge power (neglecting keeper power). The data were obtained while a beam was extracted. The center of the cathode body exhlbited the highest temperatures.

(Cathode tip temperatures were not measured.) Its temperature increased with discharge current but showed minor changes with discharge voltage. The front of the anode was at the next highest temperature, approaching $500^{\circ} \mathrm{C}$ at 140 watts of discharge power. These measurements indicated that all components operated at temperatures which are believed to be as not excessive within the discharge power range tested.

\section{Conclusions}

The object of this study was to perform a pre1 iminary characterization of the performance capabilities of the 8-cm mercury ion thruster. The thruster was operated with minor modifycations with two cathode orifice geometries. Higher then baseline beam currents were attained by operating the thruster at higher discharge currents and propellant flow rates, and lower discharge voltages. The beam current was found to increase generally linearly with decreasing discharge voltage and increasing discharge current when operating with the small cathode orifice size of $0.25 \mathrm{~mm}$. Operation with the large cathode orifice size of $0.73 \mathrm{~mm}$ resulted in a two slope discharge voltage-beam current characteristic. Beam currents (or thrusts) of up to 3.8 times the baseline condition of $72 \mathrm{~mA}$ were achieved at discharge voltages as low as 22 volts with both cathode conf igurations. 0peration of the thruster at high power levels resulted in mass utilization of up to 92 percent, with the small size cathode ori- 
fice. Tests with the larger cathode orifice resulted in lower mass utilization. The ion production costs were found to be somewhat higher than baseline values for both cathode geometries tested. The thrust and specific impulse increased with increasing input power. Over the range of thruster operation, a specific impulse of 1950 to $3040 \mathrm{sec}-$ onds was obtained, whereas a thrust of between 5.3 to $20.4 \mathrm{mN}$ was achieved as compared to $4.8 \mathrm{mN}$ thrust at the baseline conditions. The highest total efficiency of 55 percent was obtained at a discharge voltage of 24 volts and thruster input power of $0.49 \mathrm{~kW}$. No attempts were made to optimize thruster perfomance.

Spectral Tine intensities of the atomic mercury, singly and doubly charged mercury lons along with atomic molybdenum were measured at various thruster operating conditions. These measurements and the knowledge of basic sputtering mechanisms appear to indicate that the lifetime of the molybdenum screen grid (one of the major life limiting components) operated at high discharge power levels should not be a significant problem.

Also temperature measurements of critical thruster components have indicated that all temperatures were within safe operating limits.

\section{Ref erences}

1. Kerslake, W. R., and Banks, B. A., "Evolution of the 1 mlb Mercury Ion Thruster System," AIAA paper 78-7118, Apr. 1978.

2. "8-Cm Mercury Ion Thruster Subsystem Users Manual," TRW, Defense and Space Systems Group, Redondo Beach, CA, July 1977.
3. Binns, B., and Smith, W. W., "Study of Electrical and Chemical Propulsion Systems for Auxiliary Propulsion of Large Space Systems, "Boeing Aerospace Co., Seattle, WA, D180-25956-1, Apr. 1980.

4. Byers, D. C., "Upper Stages Utilizing Electric Propulsion," NASA TM 81412, 1980.

5. Hudson, W. R., "NASA Electric Propulsion Program," AIAA Paper 79-2118, Oct. 1979.

6. Love 11, R., and 0'Malley, T. A., "Station Keeping of High Power Communication Sate11ites," NASA TM X-2136, 1970.

7. Mantenieks, M. A. and Wintucky, E. G., "5200 Cycle Test of an 8-Cm Diameter $\mathrm{Hg}$ Ion Thruster," AIAA Paper 78-649, Aprol 1978.

8. Rawlin, V. K., and Hawkins, C. E., "Increased Capabilities of the 30-Cm Diameter Hg Ion Thruster," NASA TM 79142, 1979.

9. Rawlin, V. K. and Mantenieks, M. A., "Effect of Facility Background Gases on Internal Erosion of the 30-Cm $\mathrm{Hg}$ Ion Thruster," AIAA paper 78-665, Apr. 1978.

10. Poesche 1, R. L., and Beattie, J. R., "Primary Electric Propuísion Technology Study, "NASA CR-159688, 1979.

11. Mantenieks, M. A., Rawlin, V. K., "Sputtering in Mercury Ion Thrusters," AIAA paper 79-2061, Oct. 1979. 
THRUSTING PERIOD PER NODE

- 6 hrs.

12

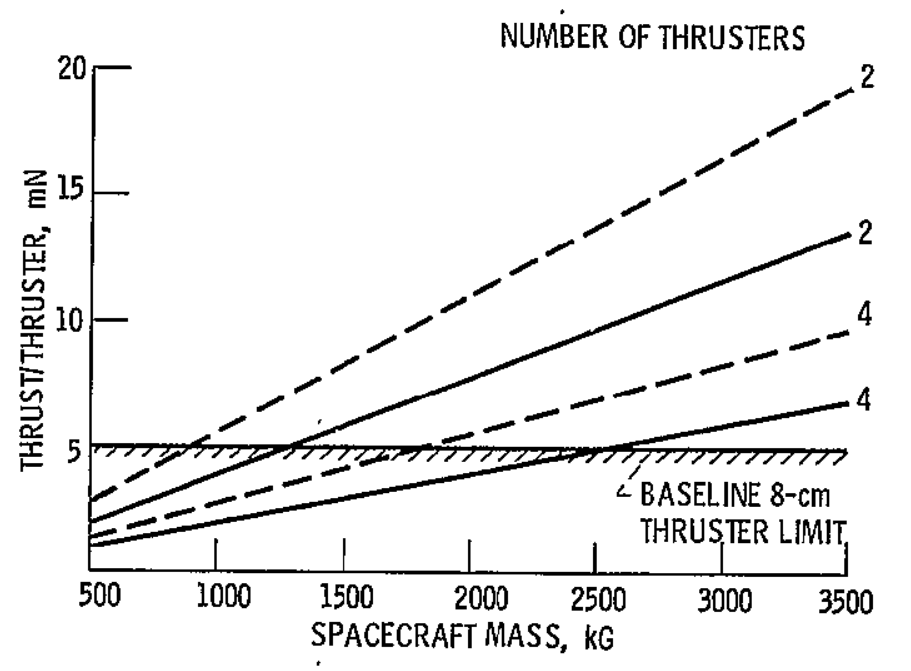

Figure 1. - Thrust requirments for $\mathrm{N}-\mathrm{S}$ station keeping. (Velocity increment: $50 \mathrm{~m} / \mathrm{sec} / \mathrm{yr}$, nodes: 2 , cant angle: $30^{\circ}$.)

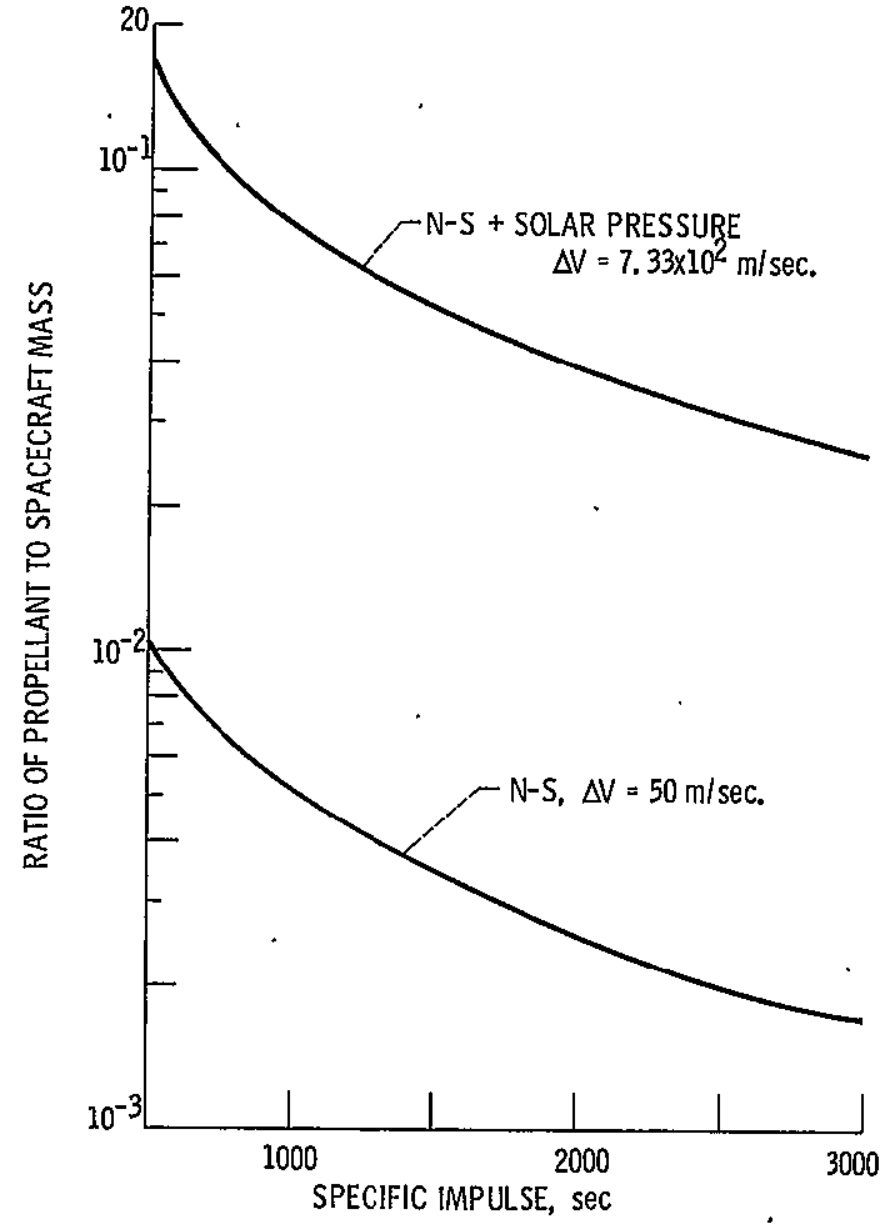

Figure 2. - One year on - orbit corrections due to solar pressure for space based radar propulsion requirements. (Continuous thruster operation, average spacecraft reflectivity: 0.3 .1 : 


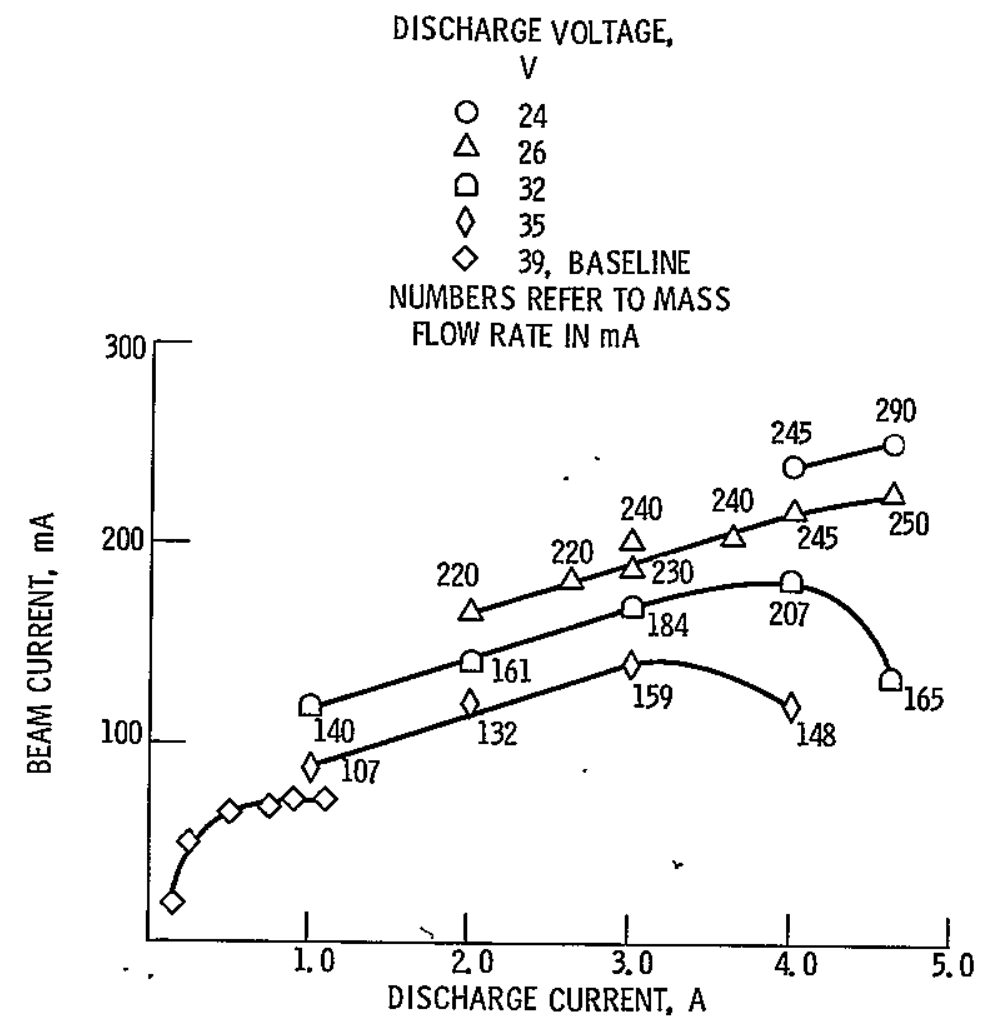

Figure 3. - Beam current as a function of discharge current. (Cathode orifice: $0.25 \mathrm{~mm}$.)

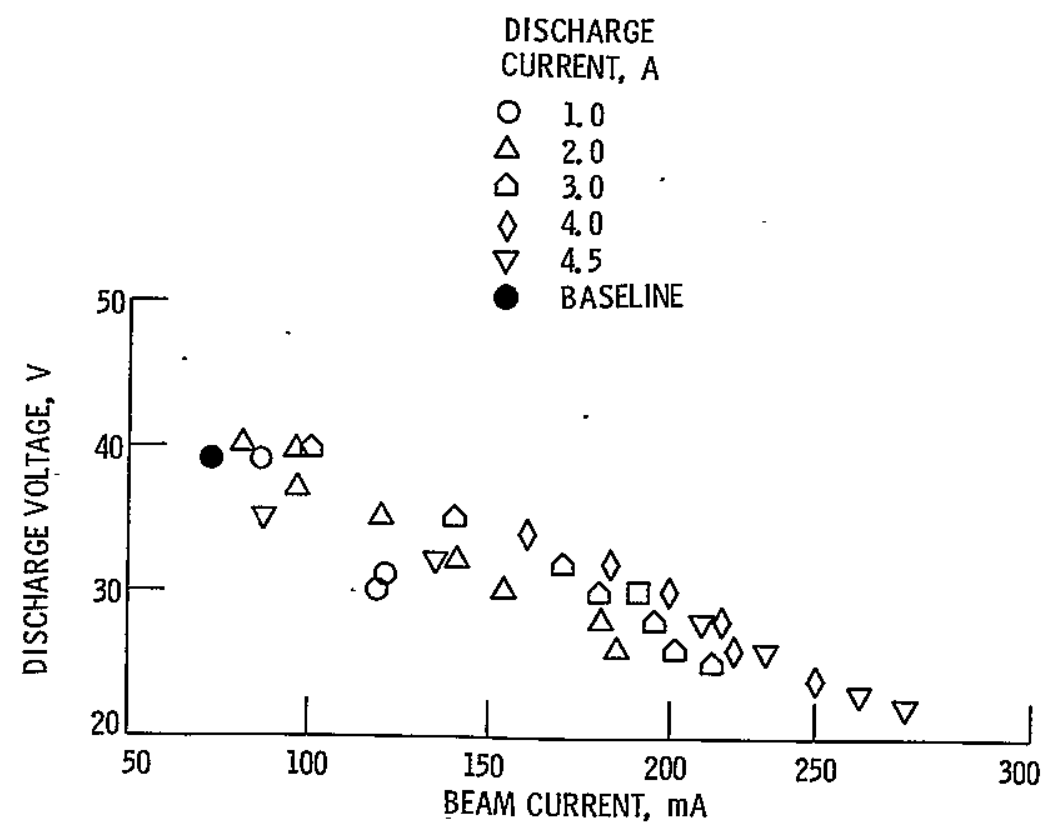

Figure 4(a). - Discharge voltage as a function of beam current. (Cathode orifice: $0.25 \mathrm{~mm}$.) 


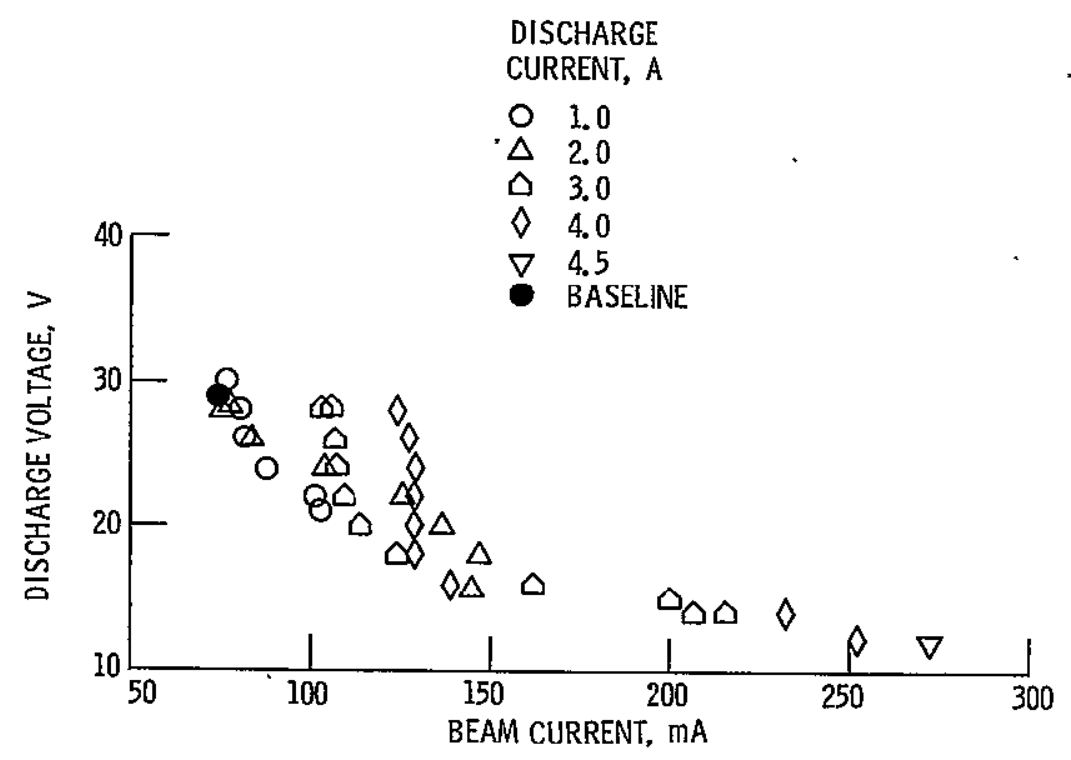

Figure $4(b)$. - Discharge.voltage as a function of beam current. (Cathode orifice: $0.73 \mathrm{~mm}$.)

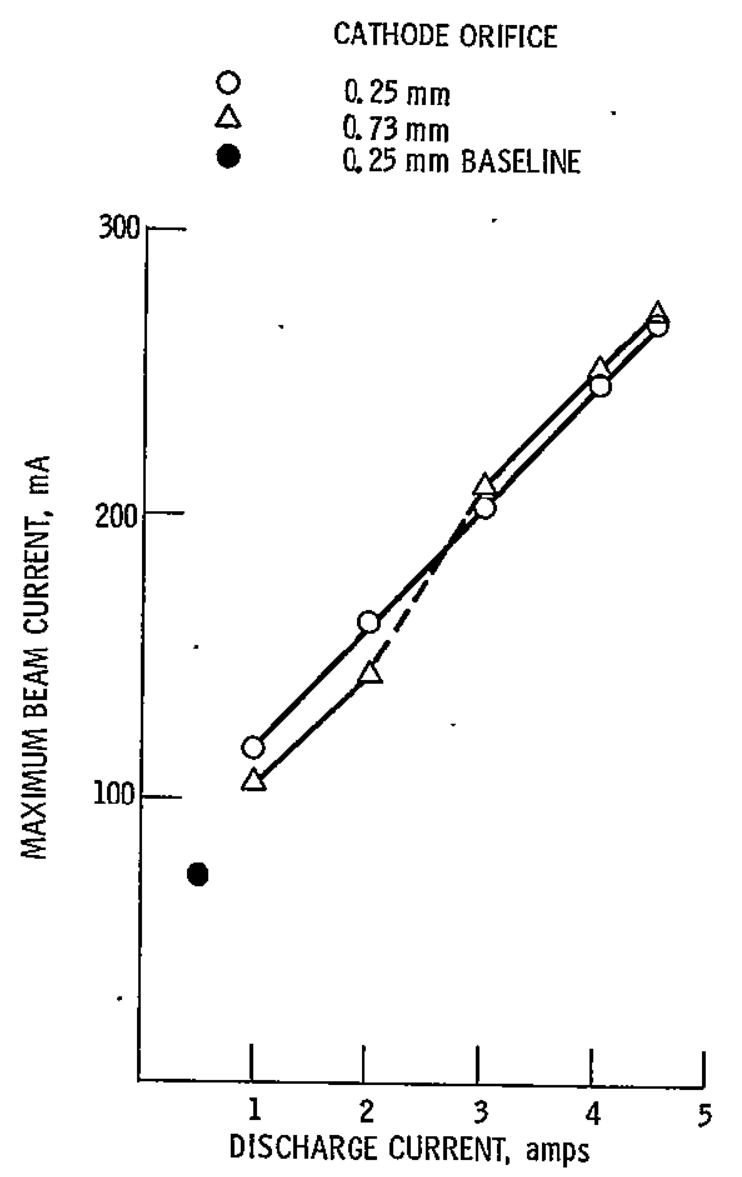

Figure 5. - Maximum beam current attainable at a given discharge current. 

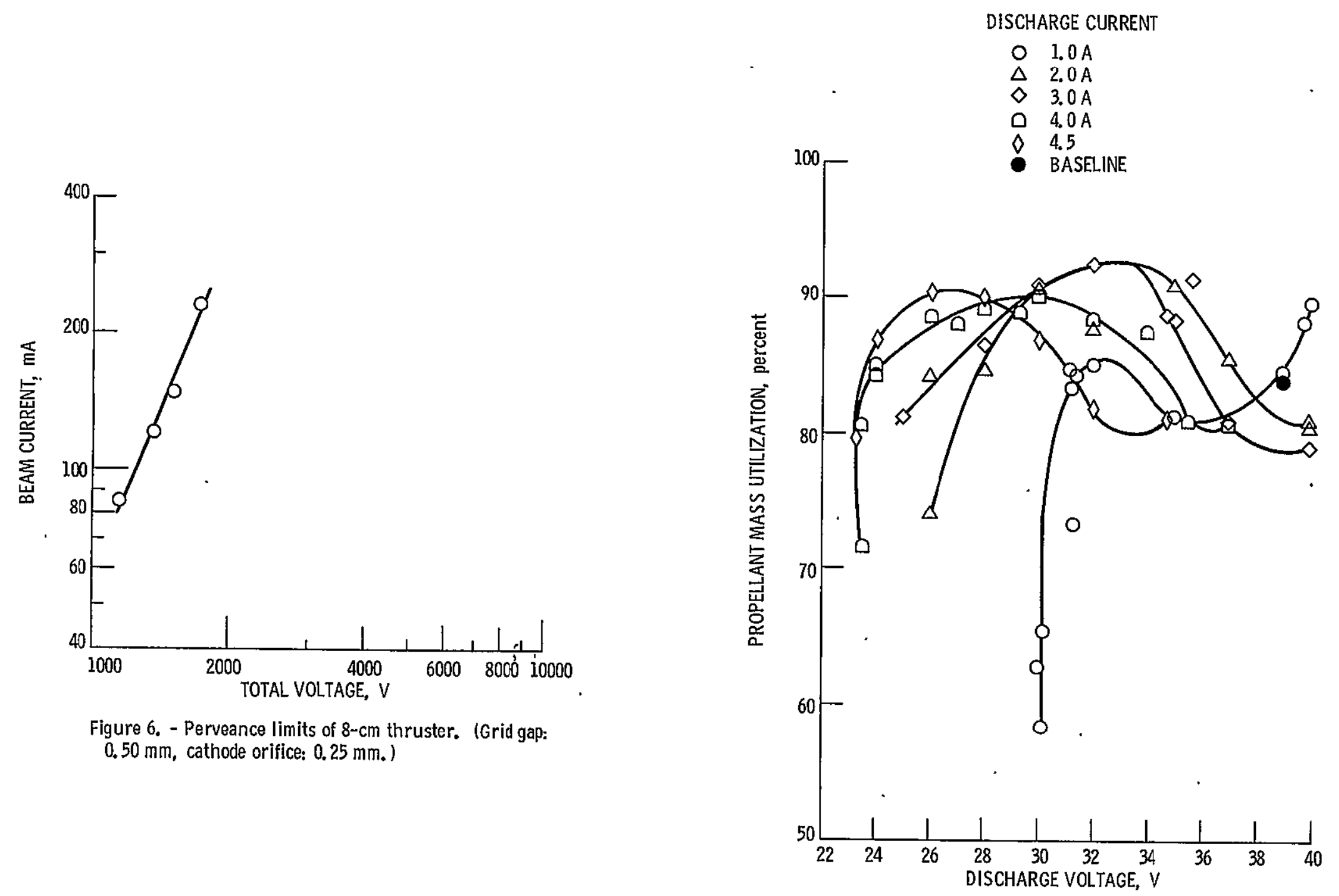

Figure 6. - Perveance limits of 8-cm thruster. (Grid gap: $0.50 \mathrm{~mm}$, cathode orifice: $0.25 \mathrm{~mm}$.)

Figure 7(a). - Propellant mass utilization as a function of discharge voltage. (Cathode orifice: $0.25 \mathrm{~mm}$.) 


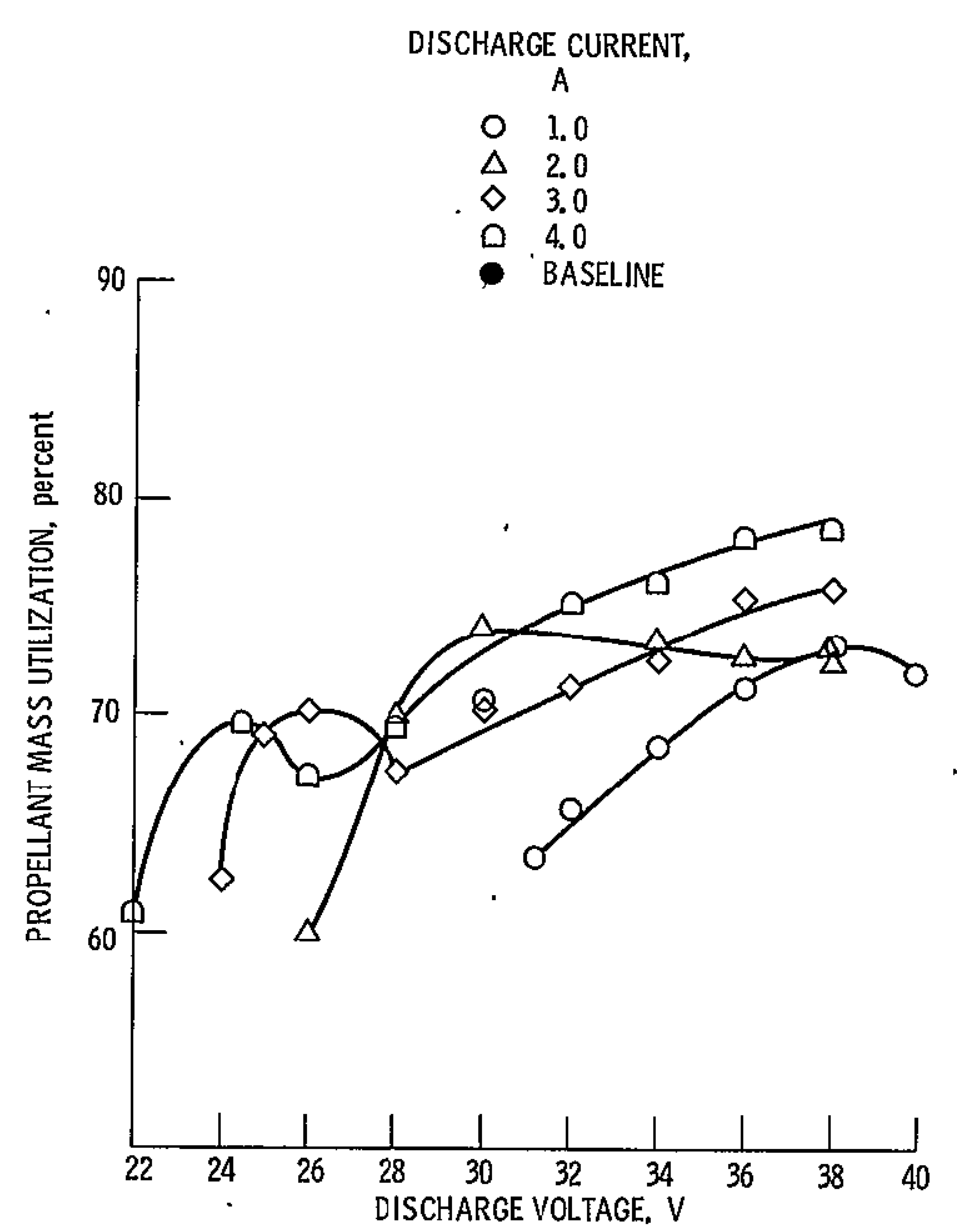

Figure 7(b). - Propeliant mass utilization as a function of discharge voltage. (Cathode orifice: $0.73 \mathrm{~mm}$.)

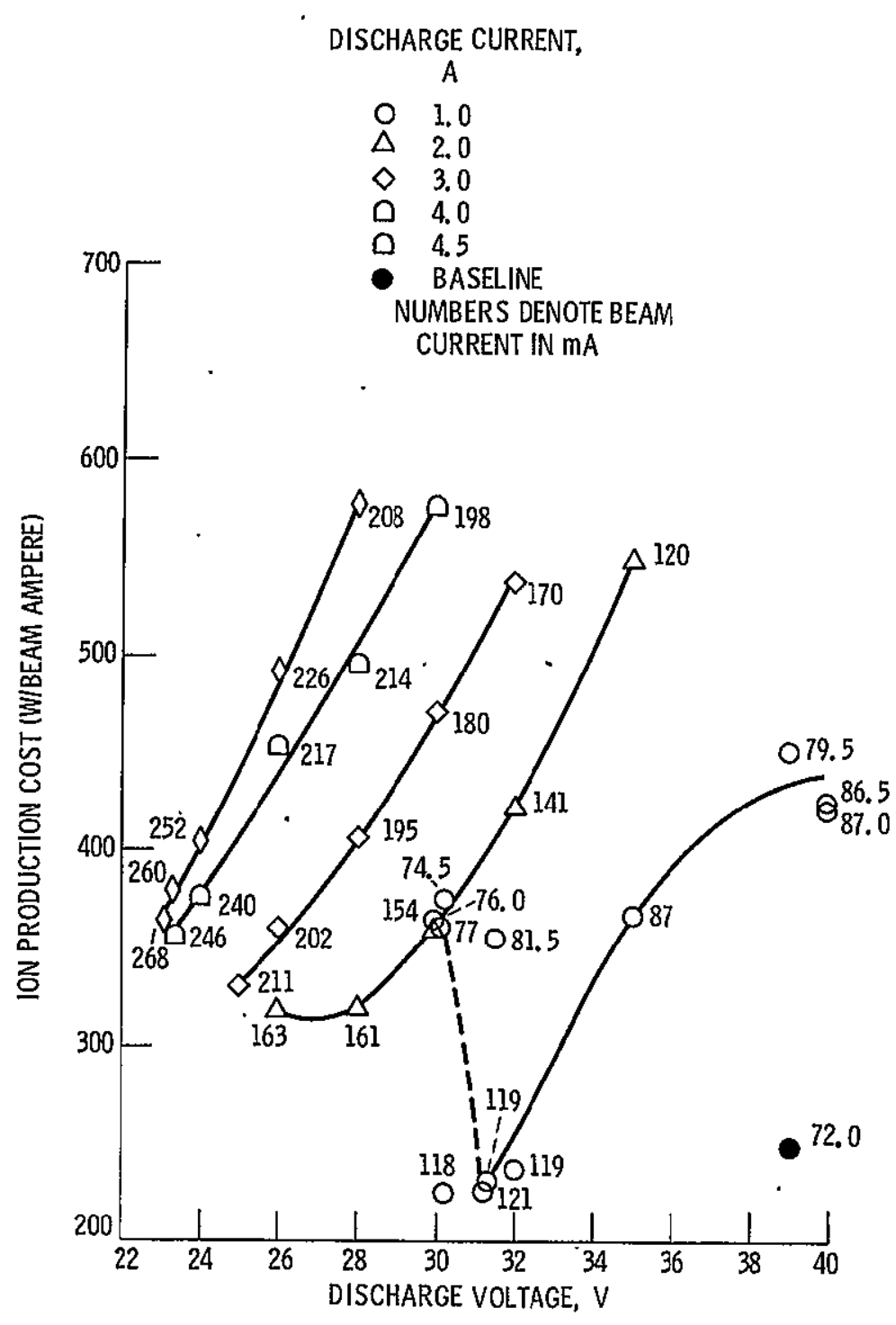

Figure 8. - Ion production cost as a function of discharge voltage. (Cathode orifice: $0.25 \mathrm{~mm}$.) 


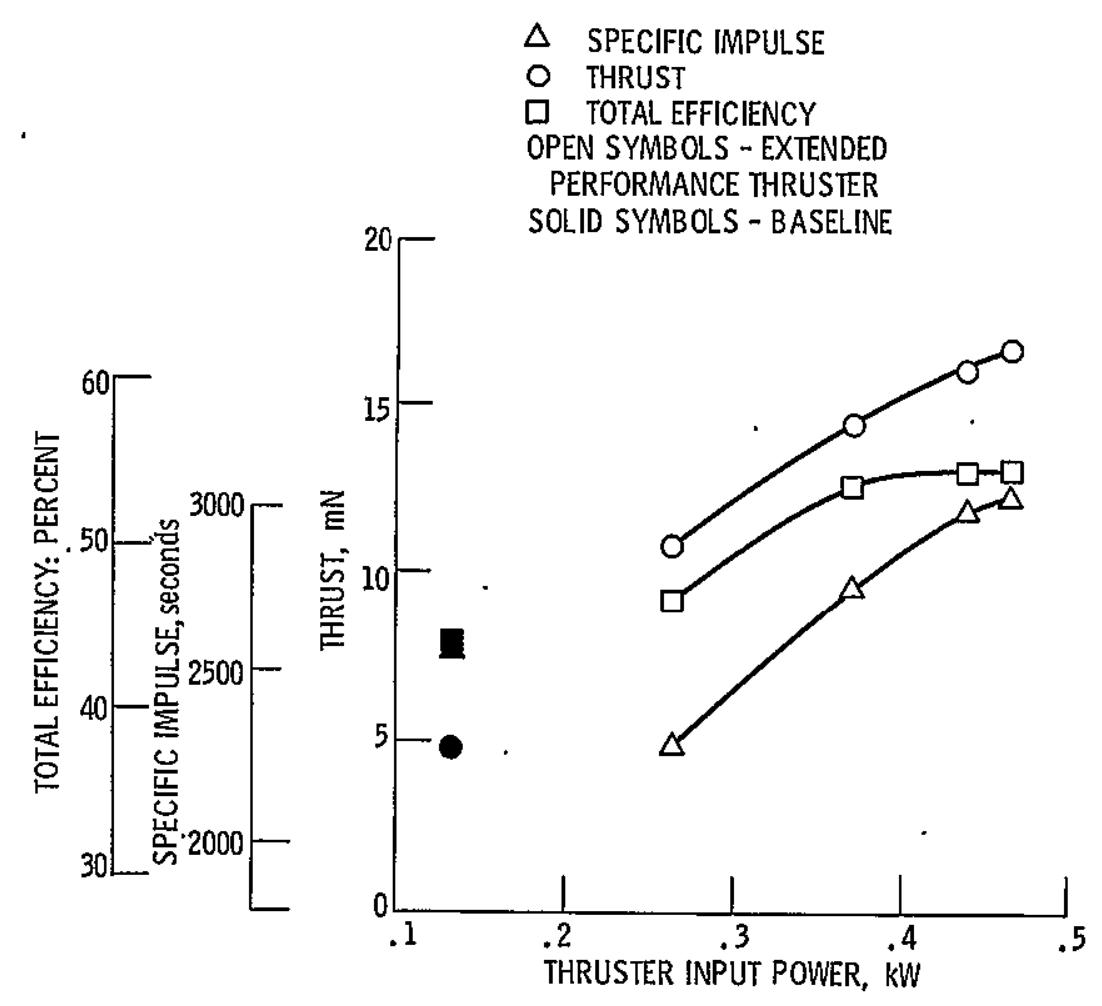

Figure 9. - Overall 8-cm thruster performance. (Discharge voltage: $26 \mathrm{~V}$, cathode orifice: $73 \mathrm{~mm}$, thrust loss factor: 0.95.$)$
DISCHARGE VOLTAGE, $V$

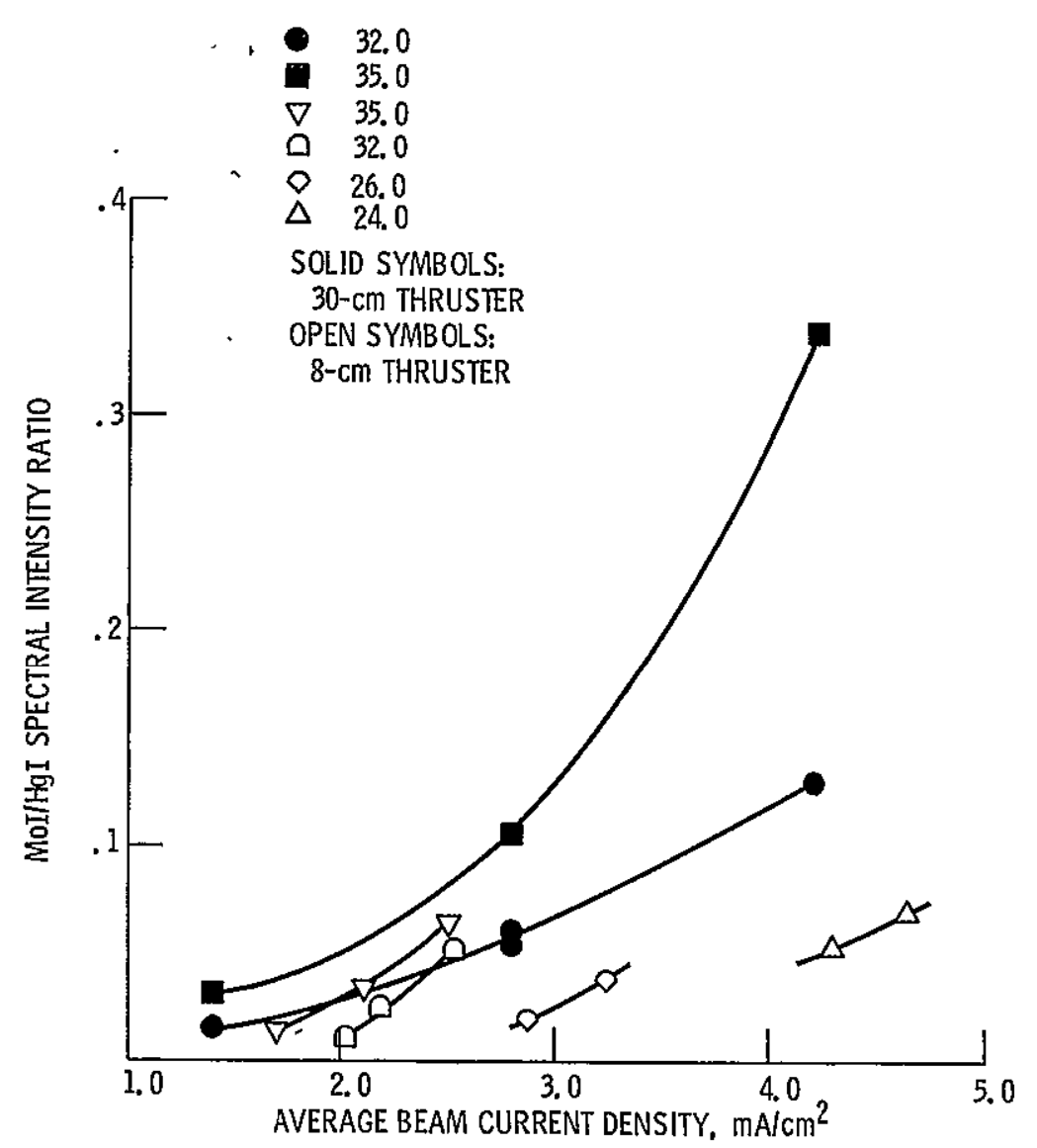

Figure 10. - Comparison of MoI/HgI line intensities as a function of average beam current density of the 30 and $8 \mathrm{~cm}$ (with $0.73 \mathrm{~mm}$ cathode orifice) thrusters. 


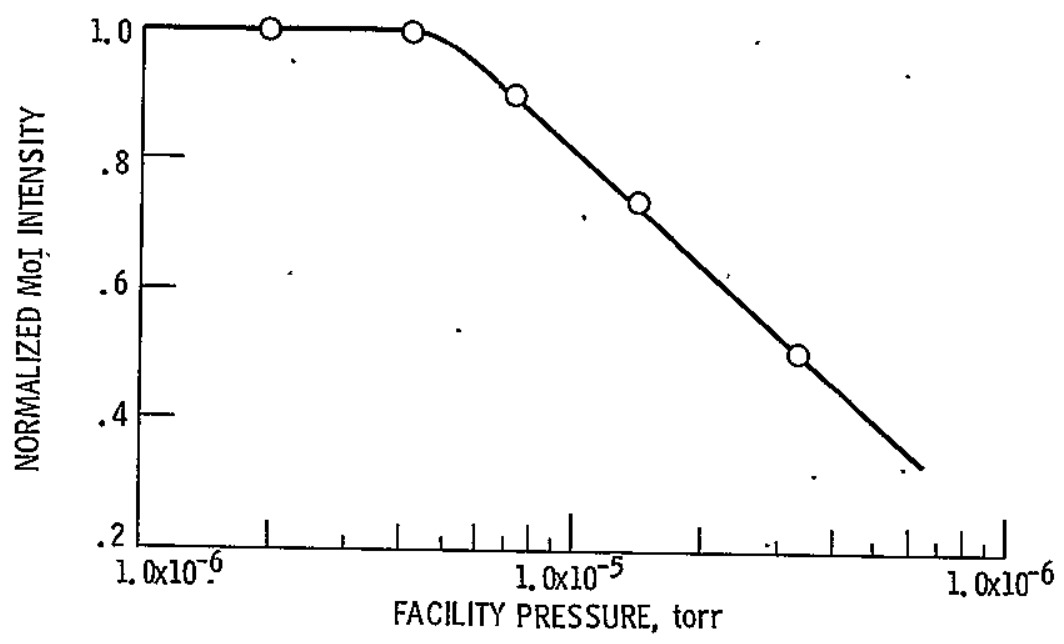

Figure 11. - Mo intensity as a function of facility pressure with $\mathrm{N}_{2}$ added. (Beam current: $204 \mathrm{~mA}$ : discharge voltage: $24 . \mathrm{V}_{*}$; cathode orifice: 0.73 $\mathrm{mm}$; po load pressure: $4 \times 10^{-5} \mathrm{~Pa},\left(3 \times 10^{-7}\right.$ torr); thruster on pressure: $7 \times 10^{-5} \mathrm{~Pa},\left(5.5 \times 10^{-7}\right.$ torr).

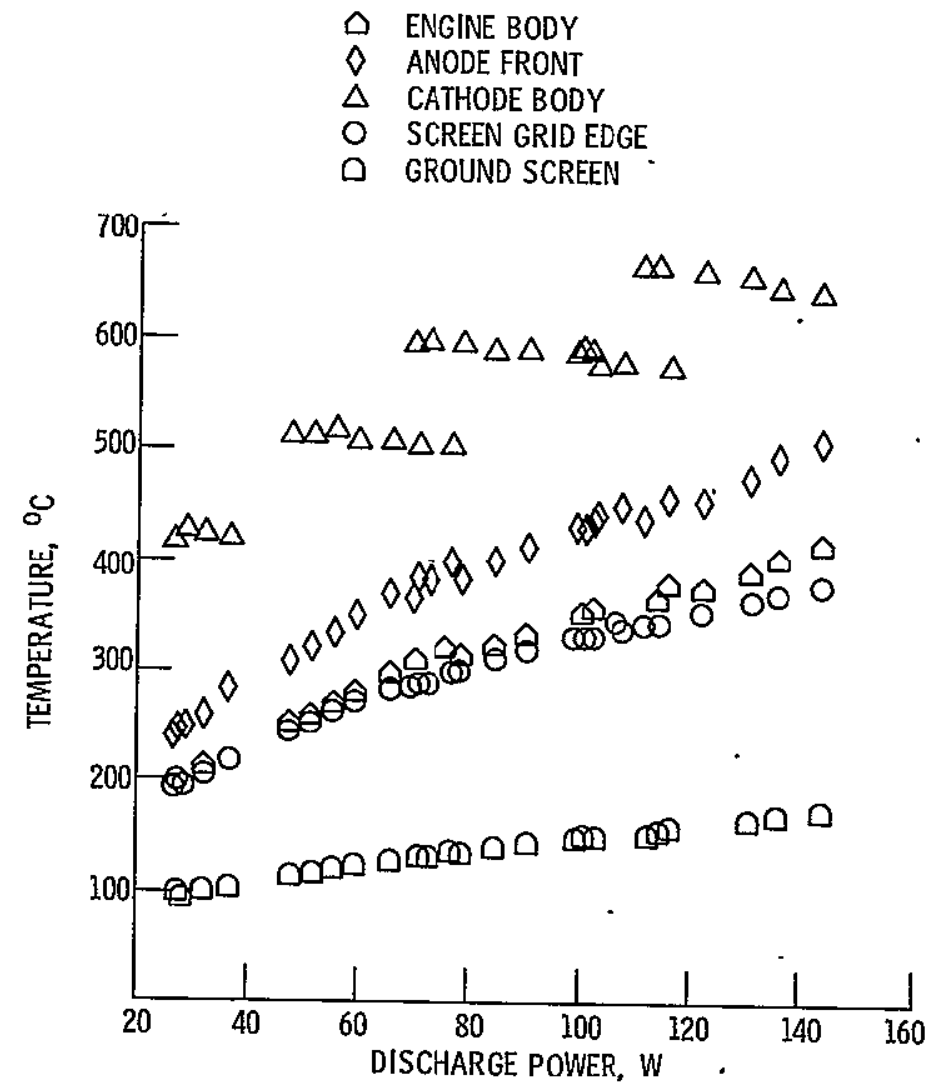

Figure 12. - Temperatures of various 8-cm thruster components. (Cathode orifice: $0.25 \mathrm{~mm}$.) 


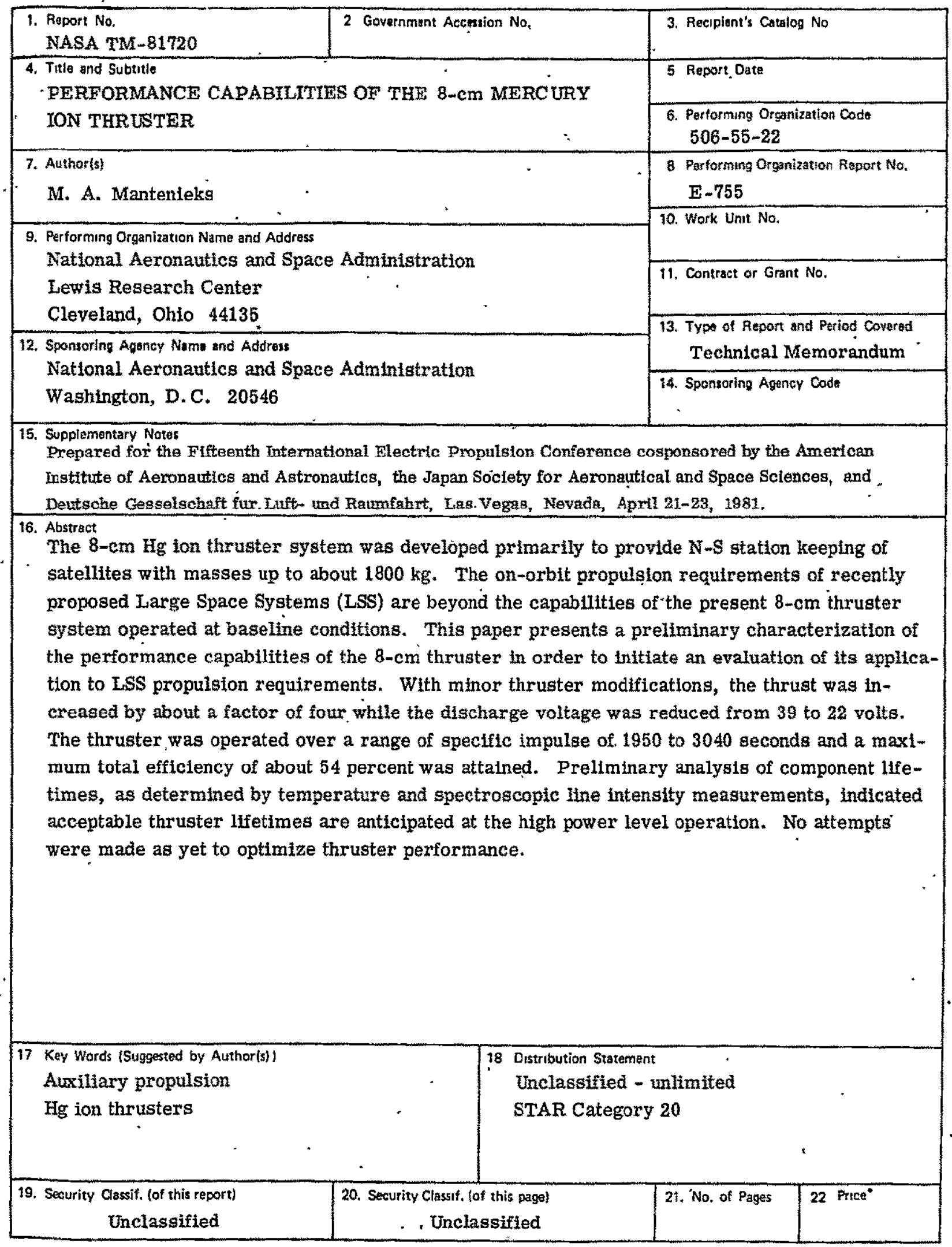

* For sale by the Nationai Technical Information Service, Springtıeld, Vırginia 22161 
National Aeronautics and Space Administration

Washington, D.C.

20546

Official Business

Penalty for Private Use, $\$ 300$
SPECIAL FOURTH CLASS'MAIL BOOK

Postage and Fees Paid National Aeronautics and Space Admıntstration NASA-451

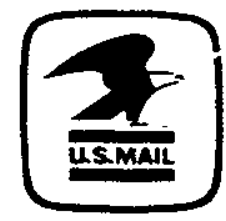


NASA FORMAL REPORT 